After four years' service, I was relieved from the charge of the hospital by Dr. Waters Smith, SeptI, 1847. A board of medical officers, after examination, reported substantially that the hospital and laboratory were in a satisfactory condition. I enclose a copy of an official letter, in reference to the subject, addressed to me by Dr. Harris.

Dr. Smith continued the work of the laboratory, adding from time to time to its apparatus and facilities until his death, in August, I 850. In September of the same year I was again placed temporarily in charge of the establishment, hospital and laboratory, and held it until some time in December, when I was relieved by Dr. Bache, immediately after his return from a cruise on the coast of Brazil, where he had served as surgeon of the fleet.

Dr. Bache took great pains to improve and extend the laboratory department. Under his skillful management it became an admirable pharmaceutical manufactory. When the term of his service as surgeon of the hospital had expired, I853, he was relieved from the care of the hospital and appointed Director of the Naval Laboratory, which was then made a station or post distinct from the hospital. He was placed on the "retired list" Feb. r, i 863 , but was still continued Director of the Naval Laboratory until September, I87 I. During the rebellion he performed the duties of the uffice, which were arduous and important, to the entire satisfaction of the Government, and therefore with credit to himself.

'This brief account of the origin and growth of the Naval Laboratory is, I think, enough to show that the statement that Dr. Bache "established" it is not quite correct.

There are other inaccuracies in the notice. If the official record is reliable, Dr. Bache was born February $\mathrm{I}$, and not February 7, I80I, as stated. 'The Navy Register does not show that he was at any time "on furlough." He was a resident in Gambier, Ohio, in I $84 \mathrm{I}$, " on leave," and I conjecture that it was about this time that he was professor of natural philosophy and chemistry in Ken yon College. Dr. Bache, I believe, never claimed to teach "the natural sciences," or any department of natural history.

We have in the navy, Francis M. Gunnell, Medical Director, and Robert H. Gunnell, Passed Assistant Engineer, but none named J. N. Gunnell, who is credited with forwarding the notice. This may be an erratum of the printer.

If the testimony herein submitted conveys sufficient evidence that the error indicated is manifest, I request you to correct it in any manner that may seem to you proper, and oblige yours,

Very truly,

W. S. W. Ruschenberger.

\section{THERAPEUTICS OF TYPHOID FEVER}

A recent editorial in "The Medical Record" (August I Ith) calls attention to the investigations of Klebs and Eberth into the pathology of typhoid fever, together with the announcement that Prof. Henri Desplats, of Lille, had made the discovery that

salicylate of bismuth is "the great desideratum" in the treatment of that disease, and concludes as follows: "In short, the perusal of this article seems to justify the hope that in the salicylate of bismuth we have a new medicament of great antiseptic value."

As it is by experience alone that the truth or falsity of a theory can be demonstrated, it is to be hoped that some one having the time and opportunity will prove whether Prof. Desplat's assertions are true or not.

In this connection, however, it is desired to call the earnest attention of the profession to the claims of sulphurous acid in the treatment of typhoid fever. A course of experimentation with the drug, extending through a period of more than twenty years, in almost every variety of zymotic disease, convinces the writer that its power over and adaptability to the medication of this variety of ailment has not been recognized and appreciated by the majority of the profession.

That it is capable of modifying both the violence and duration of typhoid fever, has been demonstrated to my own and my patients' satisfaction so many times that without the drug I should approach the treatment of a case of that disease with consid erable trepidation. Given in moderate doses during the period of dry skin and parched brown tongue, its effects are often magical.

This disease, however, is but one of the many in which sulphurous acid may be used both as a remedy and a prophylactic. The acute infectious diseases are all modified, aborted, or wholly prevented by its use.

While recognizing the latitude of the above declaration, the facts and proofs of its truth, in the writer's possession, fully justify it.

So fully is the writer persuaded of the immense value of this drug, that it is his intention, if opportunity shall permit, to submit to the profession the results of twenty years of critical study of this drug.

Most of the experiments have been made with bisulphite of soda, though in a few cases a solution of sulphurous acid diluted with glycerine has been employed, giving equally as good results, but not as well tolerated by the patient.

Let those who wish to demonstrate its utility use a saturated solution of bi-sulphite of soda in water, giving one teaspoonful every two or three hours until the system is brought fully under the influence of the drug; afterward one dose every six hours will be sufficient to maintain its effect.

Apple: River, Ili., Aug. 30, I883.

D. A. Sheffield, M.D.

\section{REVIEWS.}

Transactions of the Michigan State Medical, SOCIETY FOR THE YEAR I883. No. III. Vol. VIII.

This is a volume, or rather part of a volume, of ${ }^{3} 8$ pages, on good paper and fair type. It contains the record of proceedings and the reports and papers presented at the annual meeting of the Society in Kalamazoo, May 9 and Io, I883. After the record 